\section{Strategies for Potential Toughening of Acrylic Denture Bases Polymerized With Microwave Energy}

\author{
Rafael Leonardo Xediek Consani ${ }^{10}$, Andreia Bolzan de Paula ${ }^{2}$, Ana Paula \\ Piovezan Fugolin ${ }^{3}$, Carmem S. Pfeifer ${ }^{3}$ (D)
}

\begin{abstract}
Thiourethane additives have been shown to improve properties in several dental polymer applications. The aim of this study was to verify the effect of the addition of thiourethane oligomers and acrylamide or isobornyl-based plasticizers on the physical properties of the denture base acrylic resin polymerized with microwaves. Thiourethane oligomer (TU) was synthetized and added to microwaved acrylic resin in proportions varying between 3 and $14 \mathrm{wt} \%$. Separate experimental groups included the addition of dimethyl acrylamide (DMAM) and isobornyl methacrylate as plasticizers, at concentrations varying from 5 to $20 \mathrm{wt} \%$. Samples were polymerized using microwave energy at 500 Watts for $3 \mathrm{~min}$, deflasked at room temperature, stored in water at $37^{\circ} \mathrm{C}$ for $24 \mathrm{~h}$, and evaluated for: linear dimensional change, gloss, Knoop hardness, surface roughness, impact strength, yield strength, elastic modulus, toughness, yield strength, viscosity, glass transition temperature and network heterogeneity, and water sorption/solubility. Data were analyzed with ANOVA/Tukey's post-hoc test $(\alpha=5 \%)$. The addition of TU led to properties that were similar or worse than the materials to which it was not added, except for dimensional stability. The impact on properties was statistically significant for all materials above $20 \%$ addition of TU. The addition of DMAM at $5 \mathrm{wt} \%$ or isobornyl methacrylate at 10 wt $\%$ improved yield strength and modulus, but increased water sorption and solubility. Except for dimensional stability, the addition of thiourethane oligomers to acrylic denture base materials compromised most tested properties. The use of DMAM and isobornyl methacrylate improved properties for selected compositions.
\end{abstract}

1Prosthodontics and Periodontology Department, Piracicaba School of Dentistry, UNICAMP Universidade Estadual de Campinas, Piracicaba, SP, Brazil ${ }^{2}$ Dental Materials Department, Piracicaba School of Dentistry, UNICAMP - Universidade Estadual de Campinas, Piracicaba, SP, Brazil 3Biomaterials and Biomechanics, School of Dentistry, Oregon Health \& Science Unviversity, Portland, OR, USA

Correspondence: Carmem S. Pfeifer, 2730 SW Moody Ave., Portland, OR, USA, $97201 \mathrm{Ph}:+1-503-494$ 3288. e-mail: pfeiferc@ohsu.edu

Key Words: denture base, acrylic resin, thiourethane, plasticizers, physical properties.

\section{Introduction}

Acrylic resins based on methyl methacrylate have been used as the main component of denture bases for many decades. Albeit not ideal, characteristics such as mechanical resistance, biocompatibility with oral tissues, possibility of repair and low cost are some advantages offered by acrylic resins (1). On the other hand, stress caused by different coefficients of thermal expansion, technique sensitivity (gypsum cast position inside the flask, base thickness) $(2,3)$, acrylic resin variation among brands (4) and molecular weight of the polymer pearls (3) may lead to poor adaptation and retention of the denture base when in use by patients. Importantly, stresses derived from the polymerization and flask cooling cause linear dimensional changes and distortion in those materials (5), and those may compromise the conventional denture stability. Therefore, improvements in mechanical properties, such as impact, flexural strength and stress reduction are desirable developments for denture base materials based on acrylic resins.

Most commercial materials for denture bases contain some sort of a crosslinking monomer in the composition, apart from the methyl methacrylate base. These crosslinkers are added to the liquid (methyl methacrylate monomer) to decrease water sorption and solubility, increase the strength and rigidity, and to improve the resistance to swelling by oral fluids. The concentration is kept relatively low because methyl methacrylate by itself forms a polymer with relatively high glass transition temperature - $\mathrm{Tg}$ $\left(100^{\circ} \mathrm{C}\right)$, in great part achieved by the entanglements among linear chains and resistance to slippage between those chains below $\mathrm{Tg}$ due to the presence of short side chains (the methyl group). In fact, in ethyl methacrylate, the $\mathrm{Tg}$ is significantly lower $\left(65^{\circ} \mathrm{C}\right)$ and it exponentially decreases as the side chain length increases (to about $20^{\circ} \mathrm{C}$ in butyl methacrylate) (6). However, due to the small molecular weight, methyl methacrylate undergoes significant shrinkage and stress during polymerization, which is why in commercial materials, the liquid monomer is mixed with pre-polymerized polymethyl methacrylate beads. In addition to crosslinkers, plasticizer molecules are usually added to the composition to decrease the brittle character of PMMA materials (7). Those plasticizers can either be extrinsic, of which therephthalate is the most 
common example, or intrinsic (7). Intrinsic plasticizers are usually preferred because they are incorporated into the polymer, and therefore, are less prone to leaching, which in turn increases the polymer stability and decreases potential toxic effects (7). Common examples of internal plasticizers include long-side chain methacrylates, such as butyl or octyl methacrylate, which are co-polymerized during denture base processing (7). In addition, acrylamide monomers have shown a concentration-dependent increase in flexural properties and thermal stability of denture bases (8). Other plasticizers can be envisioned, such as some acrylamides and isobornyl-containing monomers, which have been shown to increase toughness in other methacrylate networks (9).

In addition to small molecule crosslinkers and plasticizers, several pre-polymerized additives have been proposed in the dental literature to improve the mechanical properties of PMMA-base dentures $(10,11)$. Additives have also been proposed to improve mechanical properties and decrease shrinkage and stress $(12,13)$ in other polymeric restorative material applications, including PMMA-base dentures (14) and light-cured resin cement $(13,15)$. One such additive is composed of oligomerized thiourethanes, which have been shown to improve fracture toughness by two-fold and reduce stress by up to $60 \%$ in highly filled crosslinked networks of dental composites (15). These materials provided greater mechanical resistance through thiourethane bonds, higher degree of conversion in more homogeneous polymer networks, reduction of the volumetric shrinkage and polymerization stress, increase in stiffness, fracture resistance and flexural strength of photoactivated resin cements and methacrylate based restorative composites (15-17). Thiourethanes have also been used in mouth guard materials (18), as well as other engineering applications where greater impact resistance is desirable, such as automobile parts and coatings (19).

The incorporation of thiourethane oligomers into the composition of denture base materials may have a potential to increase its toughness and resistance to impact. In addition, other internal plasticizers, such as dimethyl acrylamide and isobornyl methacrylate, might contribute to improving the toughness of denture base materials. This is clinically-relevant due to the removable nature of dentures, which exposes them to accidental drops. In addition, the potential stress reduction is viewed as an advantage from the dimensional stability standpoint. Therefore, the aim of this study was to evaluate how the systematic incorporation of two types of internal plasticizers or thiourethane oligomers influences several clinically-relevante properties, including yield strength and modulus, impact strength, dimensional stability (linear dimensional change), gloss, hardness, surface roughness, toughness and yeld strength, viscosity and dynamic mechanical analysis (DMA). The null hypothesis was that the addition of plasticizers or thiourethanes would have no impact on the tested properties.

\section{Material and Methods}

\section{Polymeric Additive Synthesis}

The synthesis of thiourethane additives has been described in detail elsewhere (20). In brief, thiouretane oligomers (TU) were synthesized by combining 1,3-bis(1isocyanato-1-methylethyl) benzene (BDI - aromatic) with trimethylol-tris-3-mercaptopropionate (TMP), at 1:2 isocyanate:thiol molar ratio, leaving pendant thiols in solution in the presence of catalytic amounts of trimethylamine. Materials were purified by precipitation in hexanes, then rotaevaporated and characterized using mid-IR (Nicolet 6700, ThermoFisher Scientific, Madison WI, USA) and 1H-NMR (Bruker; San Jose, CA) spectroscopy. The synthesized TU has a molecular weight of approximately $5 \mathrm{kDa}^{12}$.

\section{Material Formulation}

The commercially available acrylic resin activated by microwave energy (Nature-Cryl MC; GC America, Also, IL, USA) was selected to be used as control in this study. For the materials containing $\mathrm{TU}$, the oligomer was added according to the groups described in Table 1. The additive replaced either: 1. the liquid methyl methacrylate monomer at 0 (control), 10, 20 or $30 \%$ by weight, corresponding to 4.4 , 8.8 and $13.2 \%$ of the total mass (monomer + polymer), or 2 . the polymethyl methacrylate powder at 5,10 and $20 \mathrm{wt} \%$, corresponding to $2.8,5.6$ and $11.2 \%$ of the total resulting mass (monomer + polymer $+\mathrm{TU} \%$ ). For the materials containing the plasticizers, dimethyl acrylamide (DMAM) replaced either $5,10,15$ or $20 \mathrm{wt} \%$ of the methyl methacrylate monomer, or $5,10,15$ or $20 \mathrm{wt} \%$ of the polymethyl methacrylate powder. Isoborny methacrylate was also tested as a plasticizer, added at $10 \mathrm{wt} \%$ to the methyl methacrylate monomer. No additional initiators were added to the commercial resin.

\section{Sample Preparation}

Control and experimental acrylic resin samples were made using a 3:1 polymer powder to liquid monomer ratio. The material was proportioned and manipulated according to manufacturer's instructions. The resulting mass was packed into silicone molds obtained from aluminum alloy matrices included in microwavable flasks (FRP Flask, GC America, Alsip, IL, USA), to produce specimens for the different tests. The dimensions for each specimen are detailed along with the corresponding test. Materials were polymerized in a conventional microwave oven (Sharp Carousel; Mahwah, NJ, USA) using 500 W potency for 3 
$\min$. Microwave energy was used for practical reasons in this study, and has demonstrated similar results to conventional denture processing $(21,22)$. Resulting bar samples were deflasked after flask cooling at room temperature, and finished with acrylic resin finishing and polishing stones and sandpapers with decreasing abrasiveness. The initial polishing was carried out in dental bench lathe with paste of pumice and water (Laboratory Pumice, Keystone, Gibson, NJ, USA) using brush, sequentially with paste of calcium carbonate and water (Asfer, Dental Parameter, Santos, SP, Brazil) using felt cone and rag wheel. The final polishing was done with aluminum oxide paste (Universal Polishing Paste; Kota Dental Products, Sao Paulo, SP, Brazil) and felt wheel. These samples were used for the linear dimensional change, gloss, hardness, surface roughness and impact strength.

\section{Linear Dimensional Change}

Linear dimensional change of the longer and shorter distances of bar samples measuring $65 \times 10 \times 3 \mathrm{~mm}(\mathrm{n}=10)$ were evaluated using a comparator optical microscope (Olympus, Tokyo, Japan) with an accuracy of $0.0005 \mathrm{~mm}$. The sample length value was considered as the mean of the longer distances $A-B$ and $C-D$ and of the width as the mean of the shorter distances $A-C$ and B-D.

\section{Gloss}

Gloss value of the samples $(n=10)$ was measured on the same specimes used for linear dimensional change, using

Table 1. Concentration of thiourethane oligomer and plasticizer monomers in the materials used in this study. Oligomers and plasticizers replaced part of either the monomer (methyl methacrylate) or the polymer (PMMA) used to formulate the resin for denture bases. The overall concentration refers to the total oligomer/plasticizer added in relation to the total mass of material produced, and appears italicized in this table. Overall polymer/monomer ratio was set at $3: 1$ by volume, $56: 44$ by weight, considering a density of $1.2 \mathrm{~g} / \mathrm{cm}^{3}$ for PMMA and $0.94 \mathrm{~g} / \mathrm{cm}^{3}$ for methyl methacrylate (according to product specification sheet)

\begin{tabular}{|c|c|c|c|c|c|c|c|c|}
\hline & \multicolumn{8}{|c|}{ Thiourethane } \\
\hline & \multicolumn{4}{|c|}{$\begin{array}{c}\text { Replacing } \\
\text { monomer (wt } \% \text { ) }\end{array}$} & \multicolumn{4}{|c|}{$\begin{array}{c}\text { Replacing } \\
\text { polymer (wt\%) }\end{array}$} \\
\hline & 10 & 20 & & 0 & 5 & 10 & & 20 \\
\hline $\begin{array}{l}\text { Overall } \\
\text { concentration }\end{array}$ & 4.4 & 8.8 & & 3.2 & 2.8 & 5.6 & & 1.2 \\
\hline \multirow{3}{*}{$120^{*} .05$} & \multicolumn{8}{|c|}{ Plasticizers } \\
\hline & \multicolumn{4}{|c|}{$\begin{array}{c}\text { Replacing } \\
\text { monomer (wt } \% \text { ) }\end{array}$} & \multicolumn{4}{|c|}{$\begin{array}{c}\text { Replacing } \\
\text { polymer (wt\%) }\end{array}$} \\
\hline & 5 & 10 & 15 & 20 & 5 & 10 & 15 & 20 \\
\hline $\begin{array}{l}\text { DMAM } \\
\text { - Overall } \\
\text { concentration }\end{array}$ & 2.2 & 4.4 & 6.6 & 8.8 & 2.8 & 5.6 & 8.4 & 11.2 \\
\hline $\begin{array}{l}\text { IsoB - Overall } \\
\text { concentration }\end{array}$ & - & 4.4 & - & - & - & - & - & - \\
\hline
\end{tabular}

a brightness meter (Novo-Curve Gloss Meter; Rhopoint Instruments, UK) with the light beam at 60 degrees of incidence over the sample surface. The principle of measurement of the apparatus is based on the light beam incident on the surface of the sample, at which point the instrument registers the reflected light intensity and compares it with the reference value. Four measurements at predetermined points were taken for each sample and the average was recorded as the gloss unit value (GU).

\section{Hardness}

The same specimes used for linear dimensional change $(n=10)$ were used to test Knoop hardness (Hardness Tester Struers Duramin; Ballerup, Denmark) calibrated with 100 gf load for $20 \mathrm{~s}$. Three indentations were performed in each sample, one at the center and other at each end. The average of the indentations was considered as the hardness of each sample. The evaluations were made after sample confection and room temperature storage $(24 \mathrm{~h})$.

\section{Surface Roughness}

The same specimes used for linear dimensional change $(n=10)$ were used to verify surface roughness (TR200, CV Instruments, Shandong, China). The reading (Ra- $\mu \mathrm{m}$ ) considered was the arithmetic average among peaks and valleys traveled by the active point of the rugosimeter, in the following conditions: measuring path of $2.4 \mathrm{~mm}$, wavelength length of $0.8 \mathrm{~mm}$ and speed of $0.1 \mathrm{~mm} / \mathrm{s}$. Three readings were performed on the surface of each sample, one at each end and other at center. The average recorded was considered as the roughness value of each sample.

\section{Impact Strength}

The same specimes used for linear dimensional change $(n=10)$ were subjected to the impact strength test on an Otto Wolpert Werke machine (Charpy system) with a capacity of $40 \mathrm{kpcm}$. Impact value obtained at fracture time was transformed into impact strength $\left(\mathrm{kgf} / \mathrm{cm}^{2}\right)$, using the equation:

$$
I S=\frac{F}{w x t}
$$

where: IS=impact strength $\left(\mathrm{kgf} / \mathrm{cm}^{2}\right)$; $F=$ impact at fracture time $(\mathrm{kpcm}) ; \mathrm{w}=$ sample width in the impact region $(\mathrm{cm}) ; \mathrm{t}=$ sample thickness in the impact region $(\mathrm{cm})$.

\section{Yield Strength, Elastic Modulus and Toughness \\ Mechanical properties in flexure of $25 \times 2 \times 2 \mathrm{~mm}$ bars were evaluated in 3-point bending, using a universal test machine (Instron; Canton, MA, USA) at a cross-head speed of $0.5 \mathrm{~mm} / \mathrm{min}$ until fracture (23).}


The yield strength for materials was determined as the point where the stress-strain relationship ceased to be linear. The actual values were calculated using standard procedures: application of a $0.2 \%$ strain offset line with slope equal to the modulus of the stress-strain curve. The stress value (in $\mathrm{MPa}$ ) where the experimental data and the offset line overlap was used as the yield strength. Elastic modulus (GPa) was determined from the slope of the initial linear part of the stress-strain curve, calculated according to the equation:

$$
E=\frac{F x L \times 3}{4 x b \times h \times 3 \times d}
$$

where: $\mathrm{E}=$ Elastic modulus; $\mathrm{F}=$ load in some point of the linear region of the stress-strain curve $(\mathrm{N}) ; \mathrm{L}=$ distance between the supports of the sample $(25 \mathrm{~mm}) ; b=$ sample width $(2 \mathrm{~mm}) ; \mathrm{h}=$ sample thickness $(2 \mathrm{~mm}) ; d=$ slack compensated deflection at load $\mathrm{F}$.

Toughness and yield strength (MPa) were calculated from the integration of the stress-strain curve using TW Elite software (MTS Systems Corporation, Eden Prairie, MNS, USA).

\section{Dynamic Mechanical Analysis}

$15 \times 3 \times 1 \mathrm{~mm}$ bars were used for dynamic mechanical analysis (DMA 0800; TA Instruments, New Castle, DE, USA), using a temperature sweep from -25 to $180^{\circ} \mathrm{C}$ at a heating rate of $3^{\circ} \mathrm{C} / \mathrm{min}$, in tension mode $(1 \mathrm{~Hz}$ frequency). From these experiments, the glass transition temperature ( $\mathrm{Tg}$ ) and the width at half-height of the Tan delta curve (WHH) (used to estimate polymer heterogeneity (24)) were obtained.

\section{Viscosity}

Viscosity (Pa.s) was evaluated in a cone-plate rheometer (ARES, TA Instruments, New Castle, DE, USA), in rate-sweep mode of $1 \mathrm{~Hz}$ frequency. Approximately $0.5 \mathrm{~mL}$ of each monomer (control), monomer $+10 \%$ TU; monomer $+20 \%$ TU and monomer $+30 \%$ TU $(n=3)$ were individually placed between $40-\mathrm{mm}$ diameter plates separated by a $0.3 \mathrm{~mm}$ gap.

\section{Water Sorption and Solubility (WS and SL)}

To ensure that the addition of plasticizers would not affect water sorption and solubility, the materials containg these molecules were also tested for those properties. After storage in a glass desiccator at vacuum (Merck, Durham, NC, USA) containing colloidal silica at $37^{\circ} \mathrm{C}$ for $48 \mathrm{~h}$, the samples were stored at $23{ }^{\circ} \mathrm{C}$ for $1 \mathrm{~h}$ and periodically weighed in a digital electronic balance with 0.002-g accuracy (Sartorius, Bohemia, NY, USA) until to achieve a constant weight (m1). The samples were immersed in distilled water and stored in incubator (Merck) at $37{ }^{\circ} \mathrm{C}$ for 7 days, and periodically weighed until to achieve a constant weight (m2). After, they were replaced in the desiccator at $37^{\circ} \mathrm{C}$ until to obtain a constant weight, dried and reweighed (m3).

For WS/SL values calculation, the following equations were used:

$$
\begin{aligned}
& W S=\frac{(m 2-m 3)}{m 1} \\
& S L=\frac{(m 1-m 3)}{m 1}
\end{aligned}
$$

where: $\mathrm{m} 2=$ sample mass $(\mathrm{mg})$ after immersion in water; $\mathrm{m} 3=$ sample mass $(\mathrm{mg})$ after the second drying; and $\mathrm{m} 1=$ sample mass $(\mathrm{mg})$ after the first drying.

\section{Statistical Analysis}

Data were analyzed with one-way ANOVA (TU or plasticizer addition). Multiple comparisons, where applicable, were done using Tukey's test. All tests were carried out at a level of significance of 95\%.

\section{Results}

Thiourethane Additives - Replacing Part of the Monomer

Table 2 shows the results for linear dimensional change, gloss, roughness and viscosity. The linear dimensional change values in each parameter (A or B) was statistical similar for all groups $(\mathrm{p}<0.001)$. For gloss, control and $10 \%$ TU were statistically similar, and higher than the other TU-containing groups. 20\% TU presented greater gloss than 30\% TU ( $p=0.000)$. 30\% TU showed the highest roughness, followed by the 20\% TU, then by the $10 \% \mathrm{TU}$ and 
the control, which were statistically similar $(\mathrm{p}=0.000) .30 \%$ TU showed the highest viscosity, statistically higher than 10\% TU and the control. 20\% TU had statistically similar viscosity to 10 and $30 \%$ TU ( $p=0.007$ ).

Table 3 shows the results for Knoop hardness before and after storage in water, impact strength, glass transition temperature ( $\mathrm{Tg})$, width of half height (WHH) of the Tan delta peak, and degree of conversion (Final DC). For immediate hardness, the control showed higher value with statistical difference when compared to all TU additions, which were similar to each other. For $24 \mathrm{~h}$-wet storage, control showed higher value, which was different when compared to all additions. Among them, 10\% TU showed the highest value, $30 \%$ the lowest, and $20 \%$ was intermediary, which were different from each other. There were statistically significant difference only for 10\% TU when the storage conditions were compared. For impact strength, the control presented the highest result, statistically different from all the other groups. 10 and 20\% TU had similar results. 30\% TU sowed the lowest impact strength, statistically similar to $20 \%$ TU $(p=0.015)$. Glass transition temperatures varied by $13-18^{\circ} \mathrm{C}$. The control had the highest value, similar to 30\% TU. All TU concentrations had similar $T g$ $(p=0.000)$ and showed similar homogeneous networks, however there were difference when compared to control, as evidenced by the lower width at half-height values $(p=0.000)$. In terms of final DC, while control group showed the highest results (97.54 \pm 1.58$),$ TU-containing formulations were similar and averaged on $90.4 \%$.

Table 4 shows the values of the yield strength (YS), elastic modulus (EM), and toughness. For YS, control, 10 and 20\% showed the greater values with statistical difference when compared to 30\%. For EM, 10\% TU showed the greatest value when compared to $30 \%$ being control and 20\% intermediaries. Toughness was statistically lower for the 30 wt $\%$ TU concentration compared with the control.

\section{Thiourethane Additives - Replacing Part of the Polymer}

Table 5 shows the YS, EM, Toughness, Viscosity and glass transition temperature $(\mathrm{Tg})$ and degree of conversion values for control and experimental acrylic resin samples with 5 , 10 and $20 \mathrm{wt} \% \mathrm{TU}$ additions to the polymer. EM and YS - $10 \mathrm{wt} \%$ TU was statistically greater, 20 wt $\%$ TU showed smaller value whereas control and 5 wt $\%$ TU were intermediaries; Toughness and Viscosity - Control and all TU additions were statistically similar; and $\mathrm{Tg}$ - All TU additions showed greater heterogeneity and decreased Tg when compared to control, except for $5 \%$. Regarding final DC, control and 5\% TU showed the highest results (averaged 97.55 and $99.98 \%$, respectively), whereas $10 \%$ and 20\% TU presented the lowest ones
Table 5. Means (SD) of the flexural strength (FS, MPa), flexural modulus (EM, GPa), yield strength (YS, MPa), toughness (GPa), Viscosity (Pa.s) and glass transition temperature $\left(\mathrm{Tg}-{ }^{\circ} \mathrm{C}\right)$ for denture base materials modified by the addition of several concentration of thiourethane (TU), which replaced part of the powder (polymethyl methacrylate). Means followed by the same letters in each row are statistically similar $(\alpha=0.05)$

\begin{tabular}{lcccc}
\hline & Control & $5 \% \mathrm{TU}$ & $10 \% \mathrm{TU}$ & $20 \% \mathrm{TU}$ \\
\hline YS & $62.48(11.77)^{\mathrm{ab}}$ & $59.41(11.92)^{\mathrm{ab}}$ & $63.21(3.37)^{\mathrm{a}}$ & $48.89(7.59)^{\mathrm{b}}$ \\
EM & $1.6(0.50)^{\mathrm{ab}}$ & $1.74(0.30)^{\mathrm{ab}}$ & $1.95(0.37)^{\mathrm{a}}$ & $1.42(0.19)^{\mathrm{b}}$ \\
Toughness & $1.45(0.73)^{\mathrm{a}}$ & $1.22(0.37)^{\mathrm{a}}$ & $1.08(0.32)^{\mathrm{a}}$ & $1.08(0.32)^{\mathrm{a}}$ \\
Viscosity & $0.0010(0.0008)^{\mathrm{a}}$ & $0.0016(0.0013)^{\mathrm{a}}$ & $0.0009(0.0001)^{\mathrm{a}}$ & $0.0056(0.0063)^{\mathrm{a}}$ \\
Tg & $138.5(8.89)^{\mathrm{a}}$ & $125.6(1.40)^{\mathrm{ab}}$ & $121.9(1.42)^{\mathrm{b}}$ & $120.9(0.14)^{\mathrm{b}}$ \\
Final DC & $97.55(1.58)^{\mathrm{a}}$ & $99.98(0.98)^{\mathrm{a}}$ & $83.56(3.01)^{\mathrm{b}}$ & $76.33(7.85)^{\mathrm{b}}$ \\
\hline
\end{tabular}


(averaged 83.56 and 76.33\%, respectively).

\section{Plasticizers}

Table 6 shows the YS, EM, toughness, and WS/SL values for control and DMAM replacing part of the monomer. For YS, while 15\% DMAM showed the lowest values (on average $47.9 \mathrm{MPa}$ ), 5\% DMAM presented the highest ones (on average 67.0 MPa). For EM, 5 and 20\% DMAM showed similar and greater values with statistical difference when compared to other additions, whereas 15\% presented smaller value, and control and 10\% promoted similar and intermediary values. Regarding toughness, 20\% DMAM showed the highest results (averaged $2.6 \mathrm{MPa}$ ), control and 5\% DMAM presented the lowest ones (1.4 and 1.5 MPa, respectively), and 10\% and 15\% DMAM intermediary values (1.7 and 1.8 MPa, respectively). For WS, 15\% DMAM showed greater value with statistical difference when compared to other additions, whereas control and 5\% promoted similar and lower values, and 10 and $20 \%$ presented intermediary values. For SL, control and all DMAM additions showed similar and negative values.

Table 7 shows the YS, EM, toughness, and WS/SL for control and DMAM replacing part of the polymer. For YS, 5\% and 10\% DMAM showed greater values (averaged 77.3 and $78.8 \mathrm{MPa}$, respectively) and statistically different when compared to 15\% and 20\% DMAM groups (averaged 50.8 and $35.4 \mathrm{MPa}$, respectively). For EM, 5 and $10 \%$ DMAM showed similar and greater values with statistical difference when compared to other additions, 20\% presented smaller value, and control and 15\% promoted similar and intermediary values. In terms of toughness, while 10\% DMAM showed the highest values (on average 3.1 MPa), control and 15\% DMAM presented the lowest ones (on average 1.4 and $1.6 \mathrm{MPa}$, respectively). For WS, 20\% DMAM showed greater value with statistical difference when compared to other additions, whereas control and $5 \%$ presented similar and lower values, and 10 and $15 \%$ promoted intermediary values. For SL, control and all DMAM showing similar and negative values.

Table 8 shows the YS, EM, toughness, and WS/SL values for control and $10 \mathrm{wt} \%$ IsoB replacing part of the monomer. Control and 10 wt $\%$ IsoB addition showed YS and toughness values with statistical similarity. Control showed smaller value with statistically significant difference when compared to $10 \mathrm{wt} \%$ IsoB for EM. Higher value for $10 \mathrm{wt} \% \mathrm{IsoB}$ addition with statistically significant difference was shown when compared to control for WS, whereas control and $10 \mathrm{wt} \%$ IsoB showed values without statistical difference for SL.

\section{Discussion}

Table 8. Means (SD) of the flexural strength (FS, MPa), flexural modulus (EM, GPa), water sorption (WS $\mathrm{mg} / \mathrm{mm}^{3}$ ) and solubility (SL, $\mathrm{mg} / \mathrm{mm}^{3}$ ) for denture base materials modified by the addition of several concentration of isobornyl methacrylate (IsoB), which replaced part of the liquid (methyl methacrylate). Values followed by the same letters in each row are statistically similar $(\alpha=0.05)$. Values followed by the same letters in each column are statistically similar $(\alpha=0.05)$

\begin{tabular}{lccccc}
\hline & YS & EM & Toughness & WS & SL \\
\hline Control & $61.7(13.5)^{\mathrm{a}}$ & $1.68(0.52)^{\mathrm{b}}$ & $1.5(0.7)^{\mathrm{a}}$ & $0.0176(0.0019)^{\mathrm{b}}$ & $-0.0014(0.0046)^{\mathrm{a}}$ \\
IsoB & $61.5(13.2)^{\mathrm{a}}$ & $2.47(0.24)^{\mathrm{a}}$ & $1.4(0.5)^{\mathrm{a}}$ & $0.0384(0.0120)^{\mathrm{a}}$ & $-0.0013(0.0024)^{\mathrm{a}}$ \\
\hline
\end{tabular}

\section{The purpose of the present} study was to improve the properties of acrylic resins by harnessing the increase in toughness and reduction in stress observed when thiourethane oligomers were 
added to crosslinked materials (25). In the case of TU addition, the null hypothesis was rejected, since all properties were affected by the addition of TUs, with the exception of dimensional stability, which was similar to the control. The effect on mechanical properties was contrary to expected, and in general, the addition of TU, especially at higher concentrations, led to worse results than the control. In the case of plasticizer addition, the null hypothesis is also rejected, as all properties were affected.

Many attempts to reinforce acrylic resin have been made with two purposes: 1) improve mechanical strength to prevent base fracture; and 2) improve stiffness to prevent residual resorption of the alveolar ridge and overloading to the remaining tooth or oral structures. However, improvement levels vary according to the material, commercial brand, shape, concentration, surface treatment and reinforcement position (10). Several works have assessed the incorporation of fibers, fillers and hybrid reinforcement, which have shown variable effects on porosity, wear, roughness, water sorption and solubility, color stability and mechanical properties (10). The use of thiourethanes as additives had never been tested in denture base materials, but the significant improvement it has shown for crosslinked networks used in dental composites, such as two-fold increase in fracture toughness (16) and 50\% reduction in polymerization stress (15) made it a promising strategy. The rationale was to harness the toughening effects of the low $\mathrm{Tg}$, thio-carbamate-containing additive in an attempt to improve the properties of denture bases. Recently, the combination of a crosslinking agent and a thiourethane additive on the properties of acrylic denture bases processed with microwave energy showed that the addition of a low $T g$ additive based on thiourethanes (TU) did not affect mechanical properties in flexure when used alone, but led to a decrease in $\mathrm{Tg}$ both due to the low $\mathrm{Tg}$ of the additive itself and also due to the decrease in molecular weight of the individual PMMA strands (25).

In this study, the high molecular weight TU additive was added to replace part of either the low molecular weight uncured monomer, or the pre-polymerized PMMA beads, at several different concentrations. At least in the case of monomer replacement, this was expected to decrease shrinkage, based on the decreased overall molar shrinkage coefficient (26) and reduce the amount of uncured monomer, based on the lower concentration of starting monomer and the increase conversion reported with the addition of TU (16). This finds clinical relevance, since the linear dimensional change resulting from the polymerization shrinkage, along with other factors such as the depth of the palate and shape of the alveolar arches, has been correlated with poor adaptation of the complete denture base after processing (27), as well as with the movement of the teeth regardless of the method of inclusion of the prosthesis in the flask $(28,29)$. The degree of conversion, in general, decreased with the addition of $\mathrm{TU}$, though not statistically significantly for some of the concentrations. However, the conversion in thermallyactivated systems has been reported to be above $92 \%$ (30), and at that level, any effect the TU could have is likely negligible. Instead, the lack of difference in linear dimensional change is more probably related to the fact that, when considering the overall composition of the material, the TU accounted for only 10, 20 and 30\% of the volume. In fact, in previous studies, a variation of up to $25 \mathrm{wt} \%$ in monomer content did not negatively affect the displacement of the teeth of the maxillary dentures polymerized by the conventional method in heated water or by the energy of microwaves (31). In the case of polymer replacement, no effect was expected on the dimensional stability since the monomer volume was kept constant. Therefore, this property was not evaluated for those groups. For all the other properties, as mentioned, the replacement of part of the monomer with TU negatively impacted the results. This effect was noticed above $20 \mathrm{wt} \% \mathrm{TU}$ for flexural properties (yield strength, elastic modulus, and toughness) and above $10 \mathrm{wt} \%$ for hardness, impact strength, viscosity, $\mathrm{Tg}$ and polymer heterogeneity. For hardness, as expected, the results slightly increased for the control and the $10 \mathrm{wt} \%$ TU group after water storage, likely due to the extraction of unreacted monomers (32) and improved polymer packing (31). However, for the higher concentrations of TU, the hardness after water storage either stayed the same (20 $w t \%)$ or slightly decreased (30 wt $\%$ ).

Rather than a monotonic decrease in properties with the increase in TU concentration, as observed with the monomer replacement strategy, the effects of replacing part of the polymer beads with the TU additive were more complex. Though not statistically significant, a trend was observed for increased yield strength and modulus up to $10 \mathrm{wt} \%$ TU. The properties only showed a statistically significant decrease above $20 \mathrm{wt} \%$ TU concentration. However, the glass transition temperature did decrease monotonically in this case as well, which is consistent with the low $\mathrm{Tg}$ of the oligomer itself (around $5{ }^{\circ} \mathrm{C},(20)$ ). It seems that the overall TU concentration on the mass of the material, regardless of which component it replaces (monomer or powder) has a greater influence on the results. As shown in Table 1, 30 wt $\%$ of the TU "in the liquid" corresponds to around $13.2 \mathrm{wt} \%$ concentration of TU overall. For 20 wt $\%$ of TU "in the powder", the overall TU concentration is similar: $11.2 \mathrm{wt} \%$. Regardless, the addition of TU at any level does not improve properties.

Perhaps the simplest explanation for the deleterious effects of TU addition on properties lies in the significant 
increase in viscosity observed with the addition of the even the lowest concentration tested (10 wt $\%)$, at least for the monomer replacement strategy. The increase in viscosity was expected, since the high molecular weight oligomer replaced the low molecular weight, low viscosity methyl methacrylate. In addition, the hydrogen bonding potential of the TU also likely contributed to increased viscosity. With this, the handling characteristics of the mass of the material changed. This was compounded with the decrease in glass transition temperature $(\mathrm{Tg})$, which was about $15-18^{\circ} \mathrm{C}$ lower with the addition of thiourethane. This indicates that, rather than reinforcing the polymer, the presence of the oligomer impaired polymer packing and facilitated chain slippage in polymethyl methacrylate above its $\mathrm{Tg}$. This was true in spite of the fact that the TU promoted multiple points of crosslinking via chain transfer reactions of its pendant thiols and the propagation methacrylate chains (33).

Importantly, the presence of thiol functionalities within free-radical polymerizing monomers, leads to chain-breaking events via radical transfer reactions (34). In the case of crosslinked networks, chain transfer reactions are beneficial since they allow for delayed gelation and vitrification, and ultimately, increase limiting conversion and decreased polymerization stress (15). However, in the case of linear polymers, chain transfer reactions decrease the size of each individual chain and the overall molecular weight of the polymer formed, and therefore, वं original study design, but the multiple points available for crosslinking via those shame chain-transfer reactions with the pendant thiols were expected to reinforce the polymer. However, likely due to the deleterious effect of the addition of the bulky thiourethane on polymer packing and chain slippage already mentioned, any effect the increased crosslinked could have had on improving mechanical properties was overshadowed. In fact, the broader width at half height of the tan delta curves observed in this study with the addition of thiourethanes $\left(90-180^{\circ} \mathrm{C}\right.$ compared to $110-180^{\circ} \mathrm{C}$ for the control) corroborate this argument, and indicate greater heterogeneity of the polymer formed (24).

In the case of the addition of plasticizers, both the type of molecule (DMAM or Isobornyl methacrylate) and the type of replacement (polymer or monomer phase) distinctively affected the properties of the denture base material. When DMAM was used to replace part of the polymer, a significant increase in yield strength was observed up to $5 \mathrm{wt} \%$ DMAM, and a trend was observed for increase in modulus up to $10 \mathrm{wt} \%$ DMAM, though this was not statistically significant. This was expected based on the toughening effect of DMAM in vinyl-containing networks, highligheted by the toughness results (8). This monomer has demonstrated shape memory effects, which is directly related to its ability to deform without catastrophic failure (35). Above a certain threshold, however, the intrinsically lower Tg of DMAM networks may lead to an overall drop in properties. In the case where DMAM replaced part of the monomer, as the concentration of DMAM increased, the concentration of methyl methacrylate decreased. This may explain why the use of the acrylamide monomer either did not improve or reduced the properties of the materials it was added to. In either the replacement of the monomer or the polymer, however, the use of an acrylamide in co-polymerization with a methacrylate also raises the concern of interpenetrating network formation, due to the expected differential in reactivities (36). Although this was not evaluated for these groups, it is likely that as the concentration of the acrylamide increased, the heterogeneity of the polymer also increased, and this may explain not only the drop in mechanical properties, but also help explain the increase in water sorption. The water sorption was also tested for these formulations because of the higher hydrophilicity of the acrylamide.

Finally, the use of isobornyl methacrylate as a plasticizer showed the most promising results. The replacement of 10\% of the mass of methyl methacrylate with this molecule led to almost 50\% higher flexural modulus and similar yield strength compared with the control. This was expected based on the rigidity of the isobornyl side chain, which has been demonstrated to improve the properties of other linear or lightly crosslinked networks (12). This also likely created difficulties to slippage among polymer chains, but also likely decreased polymer packing, which would explain the higher water sorption. The solubility, however, was not affected. This may help decrease cytotoxicity of those materials, especially compared with common plasticizers such as terephthalate, which are known to considerably reduce cell viability (37).

This study represents a comprehensive characterization of the mechanical properties and clinically-relevant characteristics of denture base materials modified by the addition of thiourethanes and alternative plasticizers. In general, the results demonstrate that the oligomeric additive is not suitable for this application, as all properties were negatively affected. As for the plasticizers, the addition of the rigid isobornyl methacrylate to the material improved modulus, and will be further investigated in future studies.

\section{Resumo}

Aditivos de tiouretano demonstraram melhorar propriedades de polimeros em diversas aplicações. 0 objetivo deste estudo foi verificar o efeito da adição de oligômeros de tiouretano, monômeros de acrilamida ou baseados em funcionalidade isobornil na propriedades físicas de bases de dentadura de acrílico polimerizadas em micro-ondas. 0 oligômero de tiouretano (TU) foi sintetizado e adicionado à resina acrílica em proporções variando de 3 a 14\% em peso. Dimetil acrilamida (DMAM) e isobornil metacrilato 
(IBMA) foram adicionados em formulações separadas como plastificantes em concentrações variando de 5 a $20 \%$ em peso. As amostras foram polimerizadas usando energia de micro-ondas (500 Watts oor $3 \mathrm{~min}$ ), desincluidas da mufla a temperature ambiente, armazenadas em água a $37^{\circ} \mathrm{C}$ por $24 \mathrm{~h}$, e submetidas aos testes de: alteração dimensional linear, brilho, dureza Knoop, rugosidade superficial, resistência ao impacto, tensão normal de escoamento, módulo de elasticidade, tenacidade, viscosidade, temperatura de transição vitrea e heterogeneidade da rede polimérica, além de sorção de água e solubilidade. Os dados foram analisados com ANOVA e teste de Tukey $(\alpha=5 \%)$. A adição de TU não afetou ou diminuiu todas as propriedades, exceto pela estabilidade dimensional. 0 impacto nas propriedades foi estatisticamente significante para todos os materiais em concentrações acima de 20\% de TU. Isso pode ser explicado por um encurtamento das cadeias e diminuição do empacotamento das cadeias lineares do PMMA. A adição de 5\% de DMAM ou 10\% de isobornil metacrilato melhoraram a tensão de escoamento e o módulo, mas aumentaram a sorção de água e solubilidade. Exceto pela estabilidade dimensional, a adição de oligômeros de tiouretano à bases de dentatura compostas por resina acrílica prejudicou todas a propriedades testadas. 0 uso de DMAM e isobornil metacrilato melhorou as propriedades para composições selecionadas.

\section{References}

1. Alla RK, Swamy KN, Vyas R, Konakanchi A. Conventional and Contemporary polymers for the fabrication of denture prosthesis: part I - Overview, composition and properties. Int J Appl Dent Scie 2015;1:82-89.

2. Wolfaardt J, Cleaton-Jones $P$, Fatti $P$. The influence of processing variables on dimensional changes of heat-cured poly(methyl methacrylate). J Prosthet Dent 1986;55:518-525.

3. Chen JC, Lacefield WR, Castleberry DJ. Effect of denture thickness and curing cycle on the dimensional stability of acrylic resin denture bases. Dent Mater 1988:4:20-24.

4. Consani RL, Domitti SS, Rizzatti Barbosa CM, Consani S. Effect of commercial acrylic resins on dimensional accuracy of the maxillary denture base. Braz Dent J 2002;13:57-60.

5. Kawaguchi T, Lassila LV, Tokue A, Takahashi Y, Vallittu PK. Influence of molecular weight of polymethyl (methacrylate) beads on the properties and structure of cross-linked denture base polymer. J Mech Behav Biomed Mater 2011;4:1846-1851.

6. Polymer Handbook. 4th ed. Hoboken, NJ: Wiley Interscience; 1999.

7. Anusavice KJ, Shen C, Rawls HR. Phillip's Science of Dental Materials. 12 ed:Elsevier;2013.

8. Aydogan Ayaz E, Durkan R. Influence of acrylamide monomer addition to the acrylic denture-base resins on mechanical and physical properties. Int J Oral Scie 2013;5:229-235.

9. Pahnke K, Brandt J, Gryn'ova G, Lindner P, Schweins R, Schmidt FG, et al. Entropy driven chain effects on ligation chemistry. Chem Sci 2015;6:1061-1074.

10. Gad MM, Fouda SM, Al-Harbi FA, Napankangas R, Raustia A. PMMA denture base material enhancement: a review of fiber, filler, and nanofiller addition. Int J Nanomedicine 2017;12:3801-3812.

11. Gad MM, Abualsaud R, Rahoma A, Al-Thobity AM, Al-Abidi KS, Akhtar $S$. Effect of zirconium oxide nanoparticles addition on the optical and tensile properties of polymethyl methacrylate denture base material. Int J Nanomedicine 2018;13:283-292.

12. Moraes RR, Garcia JW, Barros MD, Lewis SH, Pfeifer CS, Liu J, et al. Control of polymerization shrinkage and stress in nanogel-modified monomer and composite materials. Dent Mater 2011;27:509-519.

13. Bacchi A, Consani RL, Martim GC, Pfeifer CS. Thio-urethane oligomers improve the properties of light-cured resin cements. Dent Mater 2015;31:565-574.

14. Taner B, Dogan A, Tincer T, Akinay AE. A study on impact and tensile strength of acrylic resin filled with short ultra-high molecular weight polyethylene fibers. J Oral Sci 1999;41:15-18.

15. Bacchi A, Yih JA, Platta J, Knight J, Pfeifer CS. Shrinkage / stress reduction and mechanical properties improvement in restorative composites formulated with thio-urethane oligomers. J Mech Behav Biomed Mater 2018;78:235-240.
16. Bacchi A, Pfeifer CS. Rheological and mechanical properties and interfacial stress development of composite cements modified with thio-urethane oligomers. Dent Mater 2016;32:978-986.

17. Bacchi A, Spazzin AO, de Oliveira GR, Pfeifer C, Cesar PF. Resin cements formulated with thio-urethanes can strengthen porcelain and increase bond strength to ceramics. J Dent 2018;73:50-56.

18. McNair OD, Gould TE, Piland SG, Savin DA. Characterization of mouthguard materials: A comparison of a commercial material to a novel thiolene family. J Appl Pol Scie 2014;131.

19. Matsushima $H$, Shin J, Bowman $C N$, Hoyle CE. Thiol-Isocyanate-acrylate ternary networks by selective thiol-click chemistry. J Pol Scie, Part A: Pol Chem 2010;48:3255-3264.

20. Bacchi A, Dobson A, Ferracane JL, Consani R, Pfeifer CS. Thio-urethanes improve properties of dual-cured composite cements. J Dent Res 2014;93:1320-1325.

21. Palaskar JN, Singh S, Mittal S. Evaluation and comparison of different polymerization techniques, curing cycles, and thicknesses of two denture base materials. Indian J Dent Res 2019;30:583-589.

22. Selecman AM, Brodine BA. Poly(methylmethacrylate) Microwave Processing: A Technique Paper. J Prosthodont 2019:94-96.

23. ISO-4049. ISO 4049:2019 - Dentistry - Polymer-based restorative materials.

24. Dean KM, Cook WD, Lin MY. Small angle neutron scattering and dynamic mechanical thermal analysis of dimethacrylate/epoxy IPNs. Eur Pol J 2006;42:2872-2887.

25. Consani RLX, de Paula AB, Fugolin APP, Pfeifer CS. Effect of the combination of a crosslinking agent and a thiourethane additive on the properties of acrylic denture bases processed with microwave energy. J Mech Behav Biom Mater 2019;98:90-95.

26. Patel MP, Braden M, Davy KWM. Polymerization shrinkage of methacrylate esters. Biomater 1987;8:53-56.

27. Ajaj-Alkordy NM, Alsaadi MH. Elastic modulus and flexural strength comparisons of high-impact and traditional denture base acrylic resins. Saudi Dent J 2014;26:15-18.

28. Farias Neto A, Sousa RL, Rizzatti-Barbosa CM. The influence of double flask investing on tooth displacement in dentures processed by microwave irradiation. Gerodontology 2012;29:e924-929.

29. Consani RL, Sonehara LG, Mesquita MF, Barao VA, Caetano CR. Teeth movement in denture and implant-supported prosthesis influenced by microwave flask systems. J Oral Biol Craniofac Res 2015;5:180-184.

30. Bartoloni JA, Murchison DF, Wofford DT, Sarkar NK. Degree of conversion in denture base materials for varied polymerization techniques. J Oral Rehabil 2000;27:488-493.

31. Lopes MC, Consani RL, Mesquita MF, Sinhoreti MA, Consani S. Effect of monomer content in the monomer-polymer ratio on complete denture teeth displacement. Braz Dent J 2011;22:238-244.

32. Zissis A, Yannikakis S, Polyzois G, Harrison A. A long term study on residual monomer release from denture materials. Eur J Prosthodont Restor Dent 2008;16:81-84.

33. Pfeifer CS, Wilson ND, Shelton ZR, Stansbury JW. Delayed Gelation Through Chain-Transfer Reactions: Mechanism For Stress Reduction In Methacrylate Networks. Polymer (Guildf) 2011;52:3295-3303.

34. Berchtold KA, Lovestead TM, Bowman CN. Coupling chain length dependent and reaction diffusion controlled termination in the free radical polymerization of multivinyl (meth)acrylates. Macromol 2002;35:7968-7975.

35. Wang $F$, Yong $X$, Deng J, Wu Y. Poly(N, N -dimethylacrylamide-octadecyl acrylate)-clay hydrogels with high mechanical properties and shape memory ability. RSC Adv 2018;8:16773-16780.

36. Shaik SH, Donempudi S, Tammishetti S, Rao Garikapati K, Pal Bhadra M. Interpenetrating photopolymers for intraocular lens application. J Appl Pol Scie 2017;134:44496-444505.

37. Chang $Y$, Pan $M$, Yuan J, Liu Y, Wang $X$, Jiang $P$, et al. Morphology and film performance of phthalate-free plasticized poly(vinyl chloride) composite particles via the graft copolymerization of acrylate swelling flower-like latex particles. RSC Adv 2015;5:40076-40087.

Received June 30, 2020 Accepted September 22, 2020 